First Peoples Child \& Family Review

A Journal on Innovation and Best Practices in Aboriginal Child Welfare Administration,

\title{
(A Literature Review) Re-examining issues behind the loss of family and cultural and the impact on Aboriginal youth suicide rates
}

\section{Kristine Morris}

Volume 3, Number 1, 2007

URI: https://id.erudit.org/iderudit/1069532ar

DOI: https://doi.org/10.7202/1069532ar

See table of contents

Publisher(s)

First Nations Child and Family Caring Society of Canada

ISSN

1708-489X (print)

2293-6610 (digital)

Explore this journal

Cite this article

Morris, K. (2007). (A Literature Review) Re-examining issues behind the loss of family and cultural and the impact on Aboriginal youth suicide rates. First

Peoples Child \& Family Review, 3(1), 133-142. https://doi.org/10.7202/1069532ar

\section{Article abstract}

This paper examines child welfare issues in relation to the impact of cultural loss and/or lack of cultural identity and its correlation with suicide risk among young Aboriginal persons. 
First Peoples Child \& Family Review

A Journal on Innovation and Best Practices in Aboriginal Child Welfare

Administration, Research, Policy \& Practice

\title{
(A Literature Review) Re-examining issues behind the loss of family and cultural and the impact on Aboriginal youth suicide rates
}

\author{
Kristine Morris
}

Canadian Aboriginal children are among the most impoverished population in our nation. Not only do they routinely live in poverty, but many are at risk of physical, emotional and sexual abuse, neglect, poor health care, poor housing; they are also more likely than any other group of Canadian children to be taken from their homes and placed in the child welfare system (Blackstock, Trocmè $\&$ Knoke, 2004). They are the newest generation in a long line of Aboriginal Canadians who have been oppressed, assimilated, apprehended, discriminated against, and excluded from "mainstream" society. They also have the dubious distinction of being 5 to 6 times more likely to commit suicide than their nonAboriginal Canadian counterparts within the same age range (Lynch, 2001).

\section{Cultural Continuity: A Protective Factor against Suicide Risk}

Cultural continuity has been acknowledged as a protective factor against suicide risk (Brown, 2003; Chandler \& Lalonde, 2003; Lalonde,

2003; Quantz, 1997; RCAP, 1995; Thira, 2000). In light of this connection between cultural identity - or lack thereof - and suicide risk, I believe it is important to examine the impact of loss of culture on Aboriginal young people. In doing so, we as helping professionals will hopefully gain some insight into how we may be contributing to the cultural loss experienced by these young people, as well as how we can contribute to insulating them from such despair.

As a BSW student I have also been fortunate enough to have been raised by a long time social worker who has championed equality and Aboriginal issues for decades. I feel very strongly that it is our responsibility, as social workers, to acknowledge that child welfare practices have historically ignored the best interest of the child, separating families for generations, which has greatly contributed to the loss of cultural identity experienced by these children. As we have been part of the problem, so must we be part of the solution; it is imperative that awareness is raised around this issue, so that best practice may be redefined in terms 
of what children and their families truly need, as opposed to what agencies and funders have deemed as satisfactory service delivery. Along with this, I hope to gain insight into how we, as helping professionals, can encourage an environment where our youth are not so overwhelmed by the grief of their loss that they feel the need to take their own lives.

I will examine two aspects of the way in which so many Aboriginal children experience loss of culture; first, by virtue of being placed in non-Aboriginal foster and adoption homes, and secondly, for the children who do remain in Aboriginal communities, how they are experiencing a loss of cultural identity there. I will then look at how the grief experienced by this loss of culture manifests itself in the epidemic level of suicide rates among Aboriginal youth. Finally, I will examine how kinship care is a real possibility in contributing to healing and reconnection for youth and their communities, as well as what obstacles are preventing such initiatives from truly taking flight.

For the purposes of this paper, I will be using the term 'Aboriginal' to encompass all First Nations people in Canada. I will also interchange the terms 'child'/'children' and 'youth' when referring to young people, without any intended discrepancy in age ranges in the use of one or the other. With a topic such as cultural loss for Aboriginal people, I acknowledge that there are multiple layers that would need to be addressed in order to fully understand the complexity of the issue; this, however, is not possible within the scope of this paper, nor is it the intention of this author to attempt to give a complete representation of the lives of Canadian Aboriginal people; any attempt to do so would ignore the diversity of the First Peoples, their histories and present day lives. My focus will be, specifically, on the grief experienced by loss of culture, and how this grief manifests itself in the astronomically high suicide rates found among Aboriginal youth. My intention, in focusing on the epidemic suicide rates and the protective factors against suicide is to raise awareness among human service agencies, to bring to the attention of decision and policy makers that best practice policies must take into consideration the cultural needs of these children, so giving them the possibility to live the lives they deserve to live; to live lives they feel are worth living.

\section{Aboriginal Children in non-Aboriginal Homes: the "Best Interest" Philosophy}

Government and church directed residential schools were created with the sole purpose of assimilating Aboriginal children. Children were removed from their families, forbidden from speaking their language or participating in any of their cultural or religious practices. With the closures of residential schools, beginning in the 1960's, came the development of the child welfare system, which was created with the express purpose to protect "the best interests of the child" (Royal Commission on Aboriginal Peoples (RCAP), 1996). The definition of the 'best interests' of the child, however, was established by white bureaucrats, based on Eurocentric standards and delivery models, with no input from or recognition of traditional Aboriginal culture or kinship care systems.

What resulted was a phenomenon of huge numbers of Aboriginal children being apprehended from their families, known as the "Sixties Scoop", which was all done in the name of the 'best interest of the child'. Poor socioeconomic situations on reserves made it easy for social workers, guided by white, Eurocentric 
standards, to justify taking children away from what appeared to be a deprived, neglected life. Apprehensions, according to the 'best interest of the child' philosophy of the time, seemed preferable to providing supports or services to the families in need (Shangreaux, 2004; Kulusic, 2005). Funding allocations were provided for institutions and foster care programs (in white homes), but not for preventative and supportive programs within Aboriginal communities. With no programs in place to recruit Aboriginal homes for children in care, nor to support the families in need, the children were apprehended and placed in non-Aboriginal homes, time and time again (Palmer \& Cooke, 1996). By the 1980's, Aboriginal children in care were placed in non-Aboriginal homes 70 to 90 per cent of the time. By 1994, the number of Aboriginal children in care was six times that of non-Aboriginal children (RCAP, 1996). The current estimate is that there are between 22,500 and 28,000 Aboriginal children in the child welfare system, which is three times the highest numbers of children attending residential schools in the 1940's (Blackstock, 2003). The Sixties Scoop, evidently, did not end in the sixties as the term implies.

Every time there is an apprehension, there is a child who is separated from his or her family. What effect does this have on a child? According to researchers Canetti et al., (2000), the loss of a parent by separation is "more detrimental to the mental health of adolescents than the loss of a parent by death". These findings are echoed in an international study by Yamamoto et al. (1996), who state that the loss of a parent is rated as the most stressful event in the lives of children. It is noted that the second most stressful of events are related to "any experience that is denigrating, shaming, and embarrassing to children" (p.148). In hearing so many of the stories of children placed in nonAboriginal care, there is a recurring theme of shame at being taken from their homes, shame at having parents who - they were told - could not take care of them, and most of all shame over being identified as an Aboriginal person.

With poor access to medical services on reserves, many families were forced to send their young children into foster care temporarily in order for the child to receive medical treatment. It was not unheard of for these children to simply never be returned to their families - not because of neglect or mistreatment, but because it was thought that the children would 'do better' in a white home than they would on the reserve with their families (Kulusic, 2005). The responsibility for ensuring these medical needs are met is further exasperated by the federal and provincial government's inability to take responsibility (Lavallee, 2005).

Research also confirms that early separation of a child from his or her family, like the ones just illustrated, especially when followed by emotional deprivation, puts this child at high risk for self-harm (Fournier \& Crey, 1997). Imagine becoming ill and going to the hospital as a young child, and then simply never being returned to your family, to your home...never having the chance to see your parents, your grandparents or siblings again, just because somebody decided that you would do better in a home with strangers? It seems to me that this type of loss, of emotional deprivation, could potentially put many of us at risk of such desperate measures as suicide, as well.

Add to this the fact that children were - and continue to be - placed in cross cultural homes, and you layer on another obstacle to developing a cultural identity. Kulusic (2005), 
an Aboriginal woman who was adopted by white parents, points out that non-Aboriginal adoptive parents are unable to provide for the cultural needs of Aboriginal children because of the way in which history is told regarding Aboriginal people, and that within the dominant discourse are "myths that justify transracial adoption as a form of rescue of these children." Kulusic was told by her adoptive mother that she was lucky that she did not grow up on a reserve, that "bad things happen there". Her mother was also fond of saying that her brother, also Aboriginal - was an 'Apple' - white on the inside but red on the outside - and that it was her grand accomplishment to have "made him an "Apple"". Lisa Abel (n.d.), another Aboriginal woman adopted into a non-Aboriginal family, spoke of her feelings of depression as a child: "Now I know that I was an adoptee suffering from suppressed grief over the loss of my family, confusion over my lack of cultural identity..." Yet another young woman from Bella Coola, adopted as an infant by non-Aboriginal parents, states: "The Ministry of Social Services took me from my mother at birth on the 9th day of March 1975 and sentenced me to a life without an identity" (Lynch, 2001).

In Aboriginal societies, family has always been at the core of the community; children are welcomed into and cared for by the entire community as gifts from the spirits. Ignoring this essential foundation of Aboriginal culture is not only ignoring the best interest of the child, but is contributing to the tremendous amounts of loss and grief experienced by so many Aboriginal children. As noted in the report on Indian Child Welfare Standards in British Columbia in 1992, "the child's best interests are served when the child's family is strengthened" (McKenzie \& Seidl, 1995).

\section{Growing Up on the Reserve: Generations of Cultural Loss}

Cultural identity is said to be a major influence on our confidence in our personal identities and capacities. This is especially true within traditional Aboriginal communities, where "it is the extended family that can give true shape to the First Nations or Aboriginal child's character and identity, both as an individual and as part of a community" (Lynch, 2001). The transmission of cultural identity between generations on reserves across Canada, however, has been severely disrupted, due to decades of colonialism, cultural oppression and assimilation. Generations of families have been separated and traditional ways of life have been discouraged, even forbidden, through residential schools and later through the child welfare system. Added to these racist assimilation policies are high poverty rates, low levels of education, poor employment opportunities, inadequate housing and sanitation, as well as high incidence of addictions, physical, sexual and emotional abuse. Given all these factors, it is hardly surprising that in conditions like these, youth are more likely to feel helpless and hopeless (RCAP, 1995). The losses of cultural identity, the lack of hope for the future; these feelings of loss are believed to be associated with the growing numbers of suicides and suicide attempts among Aboriginal populations. In Figure 1, Chandler et al. (2003), illustrate the disparity between suicide rates for Aboriginal and non-Aboriginal youth; the differences are staggering. The Canadian Aboriginal community presently has the worst suicide problem of any population in the world (Quantz, 1997). This is not a cultural problem, nor is it a social problem; it is an epidemic, and it's time to make a change. 
Apparently the Royal Commission on Aboriginal Peoples agreed; they held a hearing in the 1990's, to which Aboriginal youth across Canada were invited to speak. The youth spoke more often about culture and identity than about anything else; "this sense of loss coloured virtually every statement that youth made to the Commission" (Thira, 2000). It is my belief that people intuitively know what they need; Aboriginal youth know that they are suffering from a loss of culture and a loss of family, and it's time for us to listen. As a young girl from Iqaluit, NWT said in her address to the Royal Commission on Aboriginal Peoples, "Children have dreams. Children trust grown-ups. Please don't let us down".

\section{Links Between Cultural Loss and Suicide Rates}

Psychologists Chandler \& Lalonde (1998), in researching suicide rates among Aboriginal youth in British Columbia, discovered a startling fact; while more than half the tribal councils in British Columbia experienced no suicides during the six years of their study, others suffered rates of more than 800 times the national average. Figure 2 illustrates these differences, and the range is shocking (Chandler et al., 2003). This means that 90 per cent of known suicides occurred in less than 10 per cent of the Aboriginal communities in British Columbia (cited in Brown, 2003). This led the researchers to question what differences existed between the communities with low suicide rates as compared to those with astronomically high suicide rates. Chandler and Lalonde hypothesized that the difference between the communities with high rates of suicide and those with low rates of suicide was the amount of cultural continuity that the community was able to establish. They defined certain factors of cultural continuity in their study, including; efforts to regain title to traditional lands, reestablishment of self-government, control over education, health care, police and fire services, as well as providing facilities in the community where traditional cultural events and practices could take place, including involvement by Elders, women and youth (Lalonde, 2003). Their findings concluded that "in each and every case, the youth suicide rate is lower in communities that share markers of cultural continuity" (Chandler, Lalonde, Sokol, \& Hallett, 2003). Even more remarkable was the discovery that in communities where all the above mentioned factors of cultural continuity were present, there was a complete absence of youth suicide. What is it, then, about cultural continuity that is such a strong protective factor against suicide among youth? Perhaps it is the sense of belonging, which we all need. Perhaps the autonomy gained by the communities, as a result of controlling their own governments and systems, translates into a general sense of optimism, making it easier in turn for individuals in the community to reach out to their youth and support them. Although we may not have a definitive conclusion as to why cultural continuity is a protective factor against suicide, the findings still bring hope, illustrating that although every Aboriginal community has suffered oppression and a devastating loss of culture, they have not all responded in identical ways; some communities have been successful in preserving and promoting their traditional culture and have found ways to regain control over important aspects of their communal lives (Chandler et al., 2003). Coupled with this is efforts by First Nations to control aspects of research and knowledge transformation through the implementation and use of OCAP principles (National Aboriginal Health Organization, 2004). 
It is through the discovery of these remarkable findings - that increased cultural continuity strongly correlates with decreased suicide rates - that we can say with reasonable certainty that a loss of culture is a huge contributing factor to the high suicide rates experienced in some Aboriginal communities. This is a positive discovery, in that once we are able to identify a cause, we can more readily work at a solution. This is not to say that cultural identity is the sole cause of youth suicide in Aboriginal communities, or that by increasing cultural continuity we will eradicate death by suicide completely. As I said in the opening of this paper, issues surrounding the history of colonization, oppression and marginalization experienced by Aboriginal people are multilayered and complex; there is no quick fix, no easy answer. What this research does offer, however, is evidence that Aboriginal communities that are successful in preserving their culture as well as recovering some control over the institutions that govern their collective future are also "dramatically more successful in insulating their own children against the risks of suicide" (Chandler et al., 2003).

\section{Efforts to Regain What Has Been Lost}

As with any change, any movement forward, we must begin with where we are right now. The present day reality is that there are more Aboriginal children being raised in nonAboriginal homes than there were Aboriginal children taken from their homes at the height of the residential school era, and so the issue of cultural loss and grief experienced by these children in care needs to be addressed, first and foremost.

I have already discussed the way in which Aboriginal children are experiencing grief over the loss of their families as well as the loss of their cultural identities, putting them at risk of depression, self-harm and suicide. Many Aboriginal communities, along with some children's services organizations are recognizing the need for family and cultural connections for these children, and we are beginning to see some positive initiatives around re-connecting children in care with their communities.

According to Palmer and Cooke (1996), Aboriginal children in non-Aboriginal care need opportunities to be in contact with other Aboriginal people. This paves the way for these children to develop a positive sense of identity, by placing them in an environment where they are able to spend time with role models who are proud of their culture and ancestry, and are willing to share this pride and knowledge with the children. These experiences can be valuable in the healing journey for these young people who grieve the loss of separation from their communities.

One exciting example of this, which occurred in March of 2006, was a joint initiative between Saddle Lake reserve, Blue Quills, Children's Services, and the University of Calgary's Faculty of Social Work. A number of Aboriginal children in care in Edmonton were taken to Saddle Lake reserve, along with their social worker and foster parents, where they were welcomed with a feast hosted by the Saddle Lake community. The children each received a traditional blanket made by a grandmother, were introduced to their relations, and left with a specially prepared genogram of their families (J. Lafrance, Associate Professor, University of Calgary, Faculty of Social Work, personal communication, March 15, 2006). This was a positive, important reunion for these children, for the community of Saddle Lake, and for the foster parents caring for the children. This event 
is a good example of bridging the cultural gap between the care provider, the family and the community, as well as providing the children with the roots that every one of us needs and deserves. Hopefully this event will allow for these children and their families to reconnect, and for their caregivers to gain a better sense of where the children come from.

Another initiative that provides Aboriginal youth an opportunity to reconnect with their culture is the Aboriginal Youth Council (AYC), which works as part of the National Association of Friendship Centres across Canada. All Aboriginal youth from 14-24 years old are welcome to join the AYC, where they work to "preserve and promote culture and heritage" (National Association of Friendship Centres, 2006). It is a good opportunity for young people, especially those living in urban settings, to discover their culture and to surround themselves with other Aboriginal youth who have experienced the same or similar loses.

You can look on virtually any website of any foster care or adoption organization, and you will find courses and workshops for foster parents. Among the topics covered are the issues of loss and grief, as well as cultural awareness. I am hopeful, knowing that these supports are in place for non-Aboriginal foster and adoptive parents to better understand and provide for the unique needs of the children in their care. Ideally, children would always be with their families, or at least in their communities, but until that day comes - and I am hopeful that it will come - efforts such as these have the potential of reducing the staggering losses experienced by Aboriginal children in non-Aboriginal care.

My main area of concern, when discussing Aboriginal children in care, is the need to work toward changes in child welfare practices, so that children can be cared for by their families, their extended kin, or at the least within their communities. By aiming to use the least disruptive measures possible, child welfare has the potential to be practiced in a way that is not only respectful towards the child, the family and the community, but also in a way that will strengthen the family bonds that too many Aboriginal communities have had stolen over the generations. One way in which the least disruptive measures can be exerted is through kinship care. Kinship care is not a new concept; in many cultures over time, extended kin have stepped in and helped care for children when the parents have been unable to do so. Kinship care has an advantage over foster care placement in that it reduces trauma by placing "the child with familiar family members, and maintaining continuity in the child's connection to his or her culture and family history" (Morley, 2006, p.6). In light of the protective nature of cultural continuity, as discussed earlier, against suicide, this type of care arrangement seems preferable, not only in providing cultural continuity for the child, but also towards healing and reconnection within a given community. There are initiatives that are currently working towards this paradigm shift, where Aboriginal children will, ideally, remain in their communities and maintain contact with their birth families, but there are obstacles in the way.

A huge obstacle to the successful mplementation of kinship care programs is the funding that is - or rather that is not-available. According to the First Nations Child \& Family Caring Society of Canada's Wen:De Report (2005) "there are more resources available to children who are removed from their homes than for children to stay safely in their homes" (p. 21). If a child is placed in a foster home with total 
strangers - not only to the child personally but often to the child's culture as well - the home is eligible receive health and dental coverage for the child in their care. If the same child is placed with extended kin - people they know, trust, love and understand, then the family is not eligible for the same benefits. Federal funding formulas provide child welfare agencies with funds according to the number of children they have in government care, but do not provide the same financial supports for children placed with extended kin (Child and Youth Officer for British Columbia, 2006). In addition, there is more funding provided for institutions, and foster care than there is allocated for community resources, infrastructure improvements, inadequate and overcrowded housing (Loxley, De Riviere, Prakash, Blackstock, Wien, \& Thomas Prokop, 2005). As long as these standards and legislations are in place, there will be very little incentive for and initiative on the part of child welfare workers to support and maintain kinship care programs.

\section{Conclusion}

Not every parent is the best caregiver; they may have addictions, may be neglectful, and may even be abusive, but they are, in their child's eyes, the parent none the less. The grief experienced at the loss of a parent is not diminished by the quality of parenting, a point that we, as helping professionals, would do well to remember.

There is no disputing the reality that there are numerous socio-economic disadvantages for people living on reserves, including addictions, various forms of abuse, overcrowding, poor sanitation, and poverty. It is not my intention to attempt a 'solution' to all that ails Aboriginal communities. It is, however, my intention to highlight that although there are many issues that need to be addressed in Aboriginal communities across Canada, the systematic removal of a community's future generations is of no benefit to anyone. The children are suffering terrible losses; they are like trees without roots, tossed around haphazardly without direction or purpose. The strength of any community lies in its potential for the future; without it there is no hope, there is no reason for moving forward. Children need to be connected with their families and their communities, whether they are currently in care or at risk of being placed in care in the future. Federal and Provincial governments must provide more incentives to Aboriginal communities as well as to children's services agencies so that families are given real opportunities to stay together, and that they are rewarded for doing so rather than being penalized. These communities need to be provided with the resources they require to heal and gather strength, for themselves and for future generations. It's the least we can do.

\section{Bio}

Kristine Morris is a BSW student at the University of Calgary; she is the mother of two young children, and is a second generation social worker, following in her father's footsteps. Kristine aspires to work with disadvantaged children and youth; in particular with Aboriginal children. She supports and would like to be involved in efforts towards Aboriginal cultural revitalization and kinship care initiatives for Aboriginal children in care.

\section{References}

Abel, L. (n.d.). Mental Health \& the Medicine Wheel. Redwire Magazine, 7(1). Retrieved March 11, 2006, from http://www. redwiremag.com/mentalhealth.htm.

Adoption Council of Canada (2003). Yellowhead Tribal Services' Pioneering Adoption Program Keeps Native Children on the 
Reserve. Retrieved March 10, 2006, from http://www.adoption.ca/news/031001ytsa. htm.

Blackstock, C. (2003). First Nations Child and Family Services: restoring peace and harmony in First Nations communities. In K. Kufedlt \& B. McKenzie (Eds.), Child Welfare: Connecting Research Policy and Practice, (pp. 331-342). Waterloo, Ontario: Wilfred Laurier University Press.

Brown, I. (2003). Aboriginal Health and Wellness, for the National Indian \& Inuit Community Health Representatives Organization (NIICHRO). "In Touch" Magazine, 26. Retrieved March 13, 2006, from http://www.niichro.com/2004/pdf/ INtouch/in-touch-vol-26.pdf.

Canetti, L., Bachar, E., Bonne, O., Agid, O., Lerer, B., Kaplan De-Nour, A., et al. (2000). The Impact of Parental Death Versus Separation From Parents on the Mental Health of Israeli Adolescents. Comprehensive Psychiatry, 41(5), 360368. Retrieved March 11, 2006, from http://www.sciencedirect.com.ezproxy.lib. ucalgary.ca.

Chandler, M.J., Lalonde, C.E., Sokol, B.W., Hallett, P. (2003). Personal Persistence, Identity Development, and Suicide: A Study of Native and Non-Native North American Adolescents. Retrieved March 10, 2006, from http://turtleisland.org.

Child and Youth Officer for British Columbia (2006). Special Report: Heshook-isa Tsawalk: Towards a State of Healthy Interdependence in the Child Welfare System. Retrieved August 17, 2006, from http://www.gov.bc.ca/cyo/down/heshook ish_tsawalk_special_report.pdf.
First Nations Child and Family Caring Society of Canada (2005). Wen:De Report. Retrieved August 17, 2006, from http:// www.fncfes.com/docs/WendeReport.pdf.

Fournier, S., \& Crey, E. (1997). "We Can Heal”: Aboriginal Children Today. In D. Long \& O.P. Dickason (Eds.), Visions of the Heart: Canadian Aboriginal Issues (2nd Ed.) (pp.303-330). Canada: Thomas Nelson.

Kulusic, T. (2005). The Ultimate Betrayal: Claiming and Re-Claiming Cultural Identity. Atlantis: A Women's Studies Journal, 29.2. Retrieved March 11, 2006, from http://www.msvu.ca/atlantis/vol/ 292pdf/292kulusic.PDF.

Lalonde, C.E. (2003). Counting the Costs of Failures of Personal and Cultural Continuity. Human Development, 46, 137-144. Retrieved March 11, 2005, from http://turtleisland.org.

Lavallee, T. (2005). Federally funded Manitoba First Nation children with complex medical needs. Paediatrics and Child Health, Vol. 10, No. 9. Ottawa, ON: Canadian Paediatric Society.

Loxley, L., De Riviere, L., Prakash, T., Blackstock, C, Wien, F. \& Thomas Prokop, S. (2005). Wen:de: We are coming to the light of day, pp. 87-113. Ottawa, ON: First Nations Child and Family Caring Society of Canada.

Lynch, P. (2001). Keeping Them Home: The Best Interests of Indigenous Children and Communities in Canada and Australia. Sydney Law Review, 23, 504-542. Retrieved March 12, 2006, from http://heinonline.org. ezproxy.lib.ucalgary.ca/HOL/. 
(A Literature Review) Re-examining issues behind the loss of family and cultural and the impact on Aboriginal youth suicide rates

McKenzie, B., \& Seidl, E. (1995). Child and Family Service Standards in First Nations: An Action Research Project. Child Welfare, 74(3), 633-653. Retrieved March 11, 2006, from the Child Development \& Adolescent Studies database.

National Association of Friendship Centres (2006). Retrieved March 15, 2006, from http://www.nafc.ca/ayc/htm.

National Aboriginal Health Organization. (2004). First Nations center: Ownership, control, access, and possession (OCAP) or self-determination applied to research. Journal of Aboriginal Health 1(1), 80-95.

Palmer, S., \& Cooke, W. (1996). Understanding and countering racism with First Nations children in out-of-home care. Child Welfare, 75(6), 709. Retrieved March 11, 2006, from the Child Development \& Adolescent Studies database.

Quantz, D.H. (1997). Cultural Disruption: Suicide Among First Nations Adolescents. Retrieved March 11, 2006, from http:// www.thesupportnetwork.com.CASP. cultural.htm.

Royal Commission on Aboriginal Peoples. (1995). Choosing life: special report on suicide among Aboriginal people. Ottawa: Minister of Supply and Services Canada.

Royal Commission on Aboriginal Peoples. (1996). People to people, nation to nation: Highlights from the report of the Royal Commission on Aboriginal Peoples. Retrieved March 11, 2006, from http:// www.ainc.inac.gc.ca/ch/rcap/sg/si4 e.html\#top.

Shangreaux, C. \& Blackstock, C. (2004). Staying at home: examining the implications of least disruptive measures in First Nations child and family service agencies. Ottawa, ON: First Nations Child and Family Caring Society of Canada.

Thira, D. (2000). What are the Contributing Factors to Aboriginal Youth Suicide? Through the pain: Suicide Prevention Handbook. Retrieved March 12, 2006, from http://www.nandecade.ca/article/residentialschools-77.asp.

Yamamoto, K., Davis, O.L.Jr., Dylak, S., Whittaker, J., Marsh, C., Van der Westhuizen, P.C. (1996). Across Six Nations: Stressful Events in the Lives of Children. Child Psychiatry and Human Development, 26(3), 148. Retrieved March 11, 2006, from http://library.ucalgary.ca/. 